\title{
ARTÍCULO 2329 DEL CÓDIGO CIVIL. LA INTERPRETACIÓN DE PRESUNCIÓN POR HECHOS PROPIOS EXISTE EN LA JURISPRUDENCIA
}

\author{
ARTICLE 2329 OF THE CHILEAN CIVIL CODE. JURISPRUDENTIAL \\ INTERPRETATION OF PERSONAL CONDUCT
}

\section{CAROLINA SCHIEle y JOSEFINA TOCORNAL*}

\begin{abstract}
RESUMEN: La jurisprudencia chilena generalmente interpreta el artículo 2329 del Código Civil como una confirmación de la regla del artículo 2314 del mismo cuerpo legal, en virtud de la cual se le exige a la víctima probar la culpa en materia de responsabilidad extracontractual. Sin embargo, existe una línea jurisprudencial que reconoce en esta disposición una fuente normativa autónoma en base a la doctrina sostenida por Alessandri que posibilita la presunción de culpa y de relación causal por hechos propios.
\end{abstract}

Palabras clave: presunción, culpa, hechos propios, responsabilidad civil

ABSTRACT: Chilean jurisprudence generally understands article 2329 of the Chilean Civil Code as a confirmation of the rule established in article 2314 of the same Code, in which the victim must prove negligence in Torts. However, there is a jurisprudential line which recognizes in this disposition an autonomous source of law based on Professor Alessandri's doctrine which allows the presumptions of negligence and cause-effect relation for personal conducts.

Key words: presumption, negligence, personal conducts, civil liability.

Existe una línea jurisprudencial que reconoce en el artículo 2329 del Código Civil una fuente normativa autónoma de responsabilidad civil extracontractual, sin necesidad de referirse al artículo 2314 del mismo cuerpo legal. Como Alessandri lo hizo, hace ya un tiempo, se da a este artículo una interpretación más amplia que lo literal de la disposición, sosteniendo una presunción de culpa y de relación causal por hechos propios $^{1}$. En la época del autor referido su doctrina constituía una opinión aislada ${ }^{2}$; hoy, sin

* Licenciadas en Ciencias Jurídicas, Pontificia Universidad Católica de Chile. Doctorandas del Programa de Doctorado en Derecho de la misma Universidad. Dirección postal: Facultad de Derecho, Avenida Libertador Bernardo O’Higgins 340, tercer piso, comuna de Santiago, Chile. Teléfono: (56)2-3542245. Correos electrónicos: cschiele@uc.cl; jtc@uc.cl.

${ }^{1}$ Alessandri (1943) pp. 292-305.

2 Cuando Luis Claro Solar se refiere a la culpa contractual y culpa delictual menciona el artículo 2329 del Código Civil pero conjuntamente con el artículo 2314 pues considera que ambos reflejan el mismo principio establecido por la lex aquilia (CLARO, 1937, p. 518-519). Por su parte, Orlando Tapia trata el artículo 2329 del Código Civil principalmente para hacer referencia a la idea que "todo daño" debe ser reparado y así reforzar los supuestos de los artículos 2314 a 2317 del Código Civil, entre otros (TAPIA, 1941, pp. 224, 225, 237, 310, 351, 462 y ss.). Carlos Ducci considera que se debe favorecer con esta presunción a la víctima de una actividad peligrosa liberándola de la carga probatoria (DUCCI, 1936, p. 134). 
embargo, se encuentra más acompañado ${ }^{3}$. La jurisprudencia mayoritaria no está de acuerdo con su interpretación. Considera que este artículo no hace sino repetir las ideas del artículo 2314 del Código Civil, pilar de la responsabilidad extracontractual en base a la culpa probada ${ }^{4}$.

Recordemos que Alessandri funda su opinión en diversos argumentos: la ubicación de este artículo a continuación de las presunciones de culpa por hechos de otros, de cosas o de animales". La redacción de la norma y el uso de la palabra "pueda" con un sentido diverso y más abierto que la palabra "cause"-del verbo rector del artículo 2314 causar-, por lo que debía buscársele una interpretación distinta y autónoma. Así, "pue$d a$ ", subjuntivo de poder, hace referencia a que ciertos hechos sean capaces de producir un efecto, algo probable, posible, susceptible de atribuirse a, lo más razonable de suponer, entre otras lecturas. El tercer argumento nace de los ejemplos contenidos en el artículo. Se trata de casos donde los hechos dañosos demuestran por su solo acontecimiento que lo más probable es que haya habido culpa; los hechos por sí solos son demostrativos de culpa. Acreditado dichos hechos, se da por supuesta la culpa y la relación causal. Finalmente, Alessandri sostiene que la existencia de este artículo debe tener un sentido. Es razonable suponer que cada norma tenga un objeto y no que sea

${ }^{3}$ En la actualidad la doctrina está dividida: a favor BARROS (2007) pp. 147-158 y entendemos en esta línea también a Ramos por la "evidente utilidad" de esta interpretación (RAMOS, 2006, p. 57). Rodríguez solo ve una presunción de culpa en los tres casos enumerados por el artículo 2329 del Código Civil; en el primer párrafo entiende que lo que hay es una reiteración del principio general concordante con el 2314 del mismo Código (Rodríguez, 2002, p. 209-212). Corral interpreta la norma como una presunción de causalidad pero no de culpa (CORRAL, 2003, pp. 227-230). En contra de todo tipo de presunción MEZA (2006) p. 278 y ABELIUK (2001) p. 268.

${ }^{4}$ Sin perjuicio de esta jurisprudencia relativa a las presunciones, otra parte de ella fundamenta en el artículo 2329 del Código Civil la procedencia de la indemnización de los daños extrapatrimoniales como una norma que refuerza la idea de la reparación integral del daño, en particular al enunciado de este artículo en su parte "todo daño". En este sentido, entre otros: Ojeda Ojeda, Bernardo con Editorial Jurídica Conosur Ltda., Corte Suprema, 15 de enero de 2008, rol 3070-2006, Nº Legal Publishing 38344; Guerra Azócar, Astrid Lorena con Sociedad Educacional Wessex School Ltda., Corte Suprema, 28 de mayo de 2007, causa rol 312-2006, N Legal Publishing 36389; Ramírez Maturana, Manuel con Flores Costa, José Luis y Transportes Verschae Sociedad Anónima, Corte Suprema, 31 de julio de 2006, causa rol 1212-2004, Nº Legal Publishing 34912; Valdés Muñoz, Cristián Luis con Liebsch Mundana, Ramón Nicanor, Corte Suprema, 17 de mayo de 2005, causa rol 5062-2004, No Legal Publishing 32050; Constructora San Andrés Ltda. e Inmobiliaria San Andrés Ltda. con Banco Español de Chile, Corte Suprema, 14 de marzo de 2005, causa rol 546-2004, No Legal Publishing 31860; Valenzuela Tejeda, Patricio Restituto con Financiera Conosur S.A., Corte Suprema, 9 de agosto de 2004, No Legal Publishing 30655; Soto Bustos, Javier Esteban con Banco Santander Chile, Corte Suprema, 13 de noviembre 2003, causa rol 4410-2003, No Legal Publishing 28987; Moraga Espinoza, Ana con Banco Santander, Corte Suprema, 18 de abril 2002, causa rol 19782001, No Legal Publishing 24329; Rivera Araneda, Ma Angélica con Ilustre Municipalidad de La Unión, Corte Suprema, 3 de mayo de 2001, causa rol 3176-2000, No Legal Publishing 18713 y Vidal Vidal, Delfin Alfonso con Barrientos Barrientos, Luis Jaime y Empresas de Servicios Sanitario de los Lagos S.A. (acción civil en juicio penal), Corte Suprema, 18 de mayo de 2000, causa rol 3830-1999, No Legal Publishing 16895.

${ }^{5}$ Presunción de culpa por el hecho ajeno (artículos 2320 a 2322 C.C); presunción de culpa por la ruina de un edificio (art. 2320 C.C.); presunción de culpa por un animal de que se es dueño (art. 2326 y 2327 C.C.) y presunción por las cosas que se caen o arrojan de la parte superior de un edificio (art. 2328 C.C.). 
una mera reiteración de otro anterior. En este caso, el sentido de la norma es justamente el ampliar el ámbito de la responsabilidad y beneficiar a las víctimas en aquellos casos en que los hechos hablarían por sí solos ${ }^{6}$.

En definitiva, para Alessandri la presunción del artículo 2329 se aplica cuando los hechos por sí mismos denotan culpabilidad o cuando por las circunstancias en que se produjeron es susceptible de presumirse la culpa. El mismo caso dirá en cuál de las dos hipótesis se está. Se trata de una norma no taxativa, por lo que cualquier hecho que por sí mismo o por sus circunstancias denote culpa puede beneficiarse con esta presunción. No se requiere estar en uno de los tres casos mencionados pues son meros ejemplos ${ }^{7}$.

Como señaláramos, la jurisprudencia chilena no acoge la interpretación de Alessandri y, por el contrario, mayoritariamente ha entendido que el artículo 2329 del Código Civil no hace sino confirmar la regla del artículo 2314, en cuanto a que la culpa del autor del daño es carga probatoria de la víctima ${ }^{8}$. Sin embargo, existen ciertos fallos que acogen una visión diferente de esta norma, como fuente de responsabilidad autónoma, de similar modo al que Alessandri comprende dicho artículo, los que pasamos a analizar? ${ }^{9}$

\section{CASOS DE APLICACIÓN DEL ARTÍCULO 2329 DEL CÓDIGO CIVIL COMO PRESUNCIÓN DE HECHO PROPIO:}

1. Reinal Barriga, Francisco y otros con Gasco Concepción S.A. (1998): Corte Suprema, 3 de noviembre de 1998. Causa rol 4420-1998, Fallos del Mes No 481, págs. 2600-2621.

\footnotetext{
${ }^{6}$ ALESSANDRI (1943) pp. 292-305.

7 AlESSANDRI (1943) pp. 292-305.

${ }^{8}$ La jurisprudencia en forma mayoritaria ha interpretado el artículo 2329 del Código Civil como una reiteración del artículo 2314 del mismo cuerpo legal. En este sentido, entre otros: Jhangiani, Ravi con Banco de Crédito e Inversiones, Corte Suprema, 19 de marzo de 2008, causa rol 6447-2007, No Legal Publishing 38545; Salas Moya, Alejandra del Carmen por si y en representación de su hija menor de edad contra Sepúlveda Mendoza Herman César, Ilustre Municipalidad de Pedro Aguirre Cerda y Colegio Parque Las Américas (acción civil en juicio penal), Corte Suprema, 12 de diciembre de 2007, causa rol 4962-2007, No Legal Publishing 37988; del Río Riquelme, Sylvia Elena con Banco Santander Chile, Corte Suprema, 26 de septiembre de 2006, causa rol 1428-2005, No Legal Publishing 35304; Ponce Pacheco, José Alejandro y otros con Ilustre Municipalidad de Valparaiso, Corte Suprema, 20 de julio 2005, causa rol 5369-2004, No Legal Publishing 32435; Aguayo Matamala, Ma Angélica y otros con Empresa de Servicios Sanitarios del Bío Bío S.A. o Essbio S.A., Corte Suprema, 19 de diciembre de 2005, causa rol 5682-2005, No Legal Publishing 33493; Glory Product Company Limited con Empresa Portuaria Iquique y Dirección Regional de Aduanas, Corte Suprema, 31 de agosto de 2004, causa rol 534-2003, No Legal Publishing 30761; Navarrete Aguilera, Margot del Carmen con Sociedad Indalmo S.A., Corte Suprema, 3 de abril de 2003, causa rol 49912002, No Legal Publishing 26364; Publicidad Audiovisuales Limitada con Ilustre Municipalidad de Viña del Mar, Corte Suprema, 30 de diciembre de 2002, causa rol 3117-2001, No Legal Publishing 31202 y Olivares Flores, Silvia Magdalena con Zuleta Vega, Rosa Irene, Corte Suprema, 2 de abril de 2002, causa rol 692-2002, No Legal Publishing 26334.

9 Alessandri en ningún caso estima que la norma del artículo 2329 del Código Civil establezca un responsabilidad objetiva como sentencia un contradictorio fallo la Corte de Apelaciones de Rancagua, Farfán Cabezas, Johan con Empresas Unda y Roche Ltda. y Empresa Faenadora Súper Ltda., Corte de Apelaciones de Rancagua, 21 de octubre de 2003, causa rol 19759-2003, No Legal Publishing 28643.
} 
Estando en su domicilio la noche del 13 a 14 de julio del año 1994 el matrimonio Barriga, acompañados por una visita, fallecieron todos por asfixia producida por las emanaciones de gas de ciudad suministrado por la empresa Gasco S.A. La filtración se debió a la ruptura de la cañería de empalme de la matriz de la red de distribución con la instalación domiciliaria.

A juicio de los demandantes, familiares de los tres fallecidos, es responsable de las muertes acaecidas la empresa Gasco S.A. "pues tiene el cuidado de las redes de gas e instalaciones, $y$ en el hecho se han infringido numerosas normas legales y reglamentarias; así, los arts. 28, 44 y 56 del DFL 32310, modificados por la ley 18.856 ${ }^{11}$; los arts. 2.1, 2.3, 3.2.3, 4.3.9.2 letra d), 4.3.9.3.2 del DS $93^{12}$ de 1984, de Economía. Asimismo, el deber de cuidado y diligencia que imponen los arts. 2314 y siguientes del Código Civil, y la presunción de responsabilidad envuelta en su art. 2329, resultarían también aplicables al caso"13. Por su parte, la demandada solicita se rechace la acción entablada por carecer de sustento material. Sostienen que no se puede perseguir la responsabilidad de la empresa sin que se determinen los supuestos funcionarios que han incurrido "en la falta de pericia, cuidado y diligencia"14. Alega la imposibilidad que los hechos se hubiesen sucedido de acuerdo a los relatos de los demandantes y niega haber actuado con negligencia. Sostiene "que las roturas que se pueden producir en las cañerías de distribución o en los empalmes son hechos imprevisibles y normalmente irresistibles, porque al construirse las redes se aplican todos los medios de la ciencia y la tecnología para evitar su corrosión por muchos años" 15 .

El tribunal de primera instancia, a la luz de los antecedentes aportados por las partes, y de la normativa que regula la materia ${ }^{16}$, resuelve con una doble argumentación. Por una parte señala que el artículo 56 del DFL 323 establece una "responsabilidad objetiva para el autor, pues probándose el daño, el hecho y la relación de causalidad, queda establecida legalmente su responsabilidad y, por consiguiente su obligación de indemnizar los perjuicios sin necesidad de acreditar la existencia de la culpa"17. Pero, al considerando siguiente agrega que es necesario el elemento subjetivo; "de todas maneras esa culpa está acreditada por la sola circunstancia de haberse infringido el deber de vigilancia y cuidado de las redes de distribución que pesa sobre el concesionario"18. Citando a Alessandri reafirma la idea de que estaríamos en presencia de una culpa contra la legalidad, siendo aplicable por ende el artículo 2329 del Código Civil.

${ }^{10}$ El Decreto con Fuerza de Ley No 323 es la Ley de Servicios de Gas y publicada en el Diario Oficial el 30 de mayo de 1931.

${ }^{11}$ La Ley No 18.856, que modificó la Ley de Servicios de Gas, publicada en el Diario Oficial el 2 de diciembre de 1989.

12 El Decreto Supremo No 93 del Ministerio de Economía, Fomento y Reconstrucción, de abril de 1984 aprueba el Reglamento de seguridad para la distribución y expendio de gas de ciudad.

${ }_{13}$ Considerando noveno, Tribunal de Letras de Concepción, 2 de septiembre de 1996.

${ }^{14}$ Considerando décimo, Tribunal de Letras de Concepción, 2 de septiembre de 1996.

${ }^{15}$ Considerando décimo octavo, Tribunal de Letras de Concepción, 2 de septiembre de 1996.

16 Artículo 44 del D.F.L. No 323, artículo 2.3 del D.S. No 93, de 1984 de Economía y Ley 18.856.

${ }^{17}$ Considerando décimo sexto, Tribunal de Letras de Concepción 2 de septiembre de 1996.

${ }^{18}$ Considerando décimo séptimo, Tribunal de Letras de Concepción, 2 de septiembre de 1996. 
La Corte de Apelaciones de Concepción en resolución de fecha 4 de noviembre de 1997 confirma la sentencia de instancia y reconduce su fundamento optando por la línea de presumir la responsabilidad de la empresa demandada por aplicación directa del artículo 2329 del Código Civil. Señala que una "interpretación adecuada del artículo 2329 del Código Civil debe llevar a la conclusión que él contiene una presunción de responsabilidad con relación a las actividades peligrosas respecto al que las desarrolla"19 y, en la especie, la obligación legal impuesta a Gasco S.A. no se ve desvirtuada por las alegaciones y pruebas presentadas. Por su parte, la Corte Suprema se limita a desechar el recurso de casación en el fondo intentado por la demandada.

2. Barros Martín, María Susana con Viviendas Económicas B. Alto (2000): Corte Apelaciones de Santiago, 7 de septiembre de 2000. Causa Rol 2159-1997, No Legal Publishing 21059.

La dueña de un inmueble ubicado colindante a la construcción de un edificio demanda a la empresa constructora, pues al excavar sin las precauciones necesarias cedió el terreno que sustentaba su propiedad ocasionándole daños a la misma.

La sentencia firme de la Corte de Apelaciones de Santiago reproduce la sentencia apelada y reconoce que la norma del artículo 2329 del Código Civil "establece, a juicio de esta Corte, una presunción general de culpabilidad si el perjuicio causado es consecuencia de un hecho que, por su naturaleza o por las circunstancias en que se realizó, es susceptible de atribuirse a culpa o dolo del agente" ${ }^{20}$. La sentencia hace un análisis de la norma de acuerdo a la doctrina de Alessandri. Señala que la presunción se puede desprender en primer lugar, de "la redacción misma de dicha disposición, pues al utilizarse por el legislador la expresión subjuntiva "pueda" se está queriendo aludir en general a cualquier daño que sea posible, probable o racional de imputar a malicia o negligencia" ${ }^{21}$. Se funda también en un segundo argumento, que los casos que contiene el artículo 2329 aludido, todos se refieren a hechos que suponen la característica antes anotada, en el sentido que todos ellos alteran el comportamiento normal con el que se ha proceder en las circunstancias descritas en cada ejemplo. Además, agrega que esta disposición, no puede tratarse de una reiteración de la regla general contenida en el artículo 2314 del Código Civil ${ }^{22}$, por las razones que ya hemos desarrollado anteriormente.

Aplica el sentenciador lo señalado al caso concreto, en el que una empresa constructora no ha tomado las medidas de seguridad necesarias al realizar las excavaciones para la construcción de un edificio. Ello ha causado un daño en las propiedades colindantes, situación que es "anormal" y, por tanto, es posible presumir que si se produjo daño en la construcción de la demandante, es debido a que la construc-

\footnotetext{
19 Considerandos séptimo, octavo, noveno y décimo, Corte de Apelaciones de Concepción, 4 de noviembre de 1996.

20 Considerando primero, Corte de Apelaciones de Santiago, 7 de septiembre de 2000. La redacción del fallo perteneció al abogado integrante y profesor de derecho civil Alberto Lyon.

${ }^{21}$ Considerando segundo, Corte de Apelaciones de Santiago, 7 de septiembre de 2000.

22 Considerando tercero, Corte de Apelaciones de Santiago, 7 de septiembre de 2000.
} 
tora demandada no actuó con la debida diligencia y, al no aportar la prueba necesaria que permita destruir la presunción de culpabilidad que opera en su contra, se debe concluir que los daños sufridos en la propiedad de la demandante deben ser indemnizados ${ }^{23}$.

3. Almonacid Henriquez, Jorge y otra con Corporación Fe, Unión y Esfuerzo e Ilustre Municipalidad de Puerto Montt (2000): Corte Suprema, 2 de noviembre de 2000. Causa Rol 1386-1999, No Legal Publishing 17528.

Con fecha 6 de octubre de 1992 la Sra. Vera, acompañada de su hija de 4 años, concurrió al consultorio de salud Techo para Todos para un control ginecológico de rutina. La madre fue atendida, dejando sola a la menor por aproximadamente diez minutos. Al salir del box de atención, la madre busca a la niña en el consultorio, pero la encuentra en el patio trasero flotando en el agua servida de una cámara de alcantarillado de 2,8 metros de profundidad que estaba abierta. La menor es reanimada y, luego de un largo proceso de recuperación, queda con daño cerebral difuso de carácter grave.

El padre y la madre de la menor entablaron una demanda de indemnización de perjuicios en contra de la corporación dueña del inmueble y de la municipalidad que administraba el consultorio municipal. Fundan su demanda en la responsabilidad que les cupo en el accidente de su hija, por la falta de mantención y cuidado de las instalaciones del lugar. Los demandantes sostienen que "la tapa de una cámara de desagüe abierta constituye un peligro y que por dicha negligencia cualquier persona pudo haber sufrido un daño, el cual necesariamente debe ser reparado, presumiéndose esta responsabilidad al tenor de lo previsto en los artículos 2329 y 2323 del Código Civil"24. Por su parte, las demandadas se defendieron alegando la falta de relación causal pues sería el hecho o culpa de la madre lo que permitió el accidente. La sentencia de primera instancia no invoca el artículo 2314 del Código Civil para condenar a la Ilustre Municipalidad de Puerto Montt ${ }^{25}$ sino, entre otros, el artículo 2329 No 2 del Código Civil, que dispone que son especialmente obligados a la reparación del daño "el que remueve las losas de una acequia o cañería en calle o camino, sin las precauciones necesarias para que no caigan los que por alli transitan de día o de noche".

La sentencia fue confirmada por la Corte de Apelaciones de Puerto Montt el 24 de marzo de 1999 y por la Corte Suprema el 2 de noviembre de 2000. Esta última reitera la responsabilidad de la municipalidad en tanto usuaria del inmueble e infraestructura del consultorio. El máximo tribunal considera que debió vigilar y cuidar las medidas de seguridad del recinto y su responsabilidad "se sustenta en el hecho propio y que en la especie ha consistido en la omisión de un deber de vigilancia de las medidas de seguridad en un reciento destinado a la atención del público"26.

\footnotetext{
23 Considerandos cuarto y sexto, Corte de Apelaciones de Santiago, 7 de septiembre de 2000.

${ }^{24}$ Considerando primero, sentencia de Tribunal de Letras de Puerto Montt, 27 de octubre de 1998.

25 No se dio lugar a la demanda contra la corporación. Los demandantes no acreditaron el dominio de la misma sobre el terreno donde funcionaba el consultorio.

${ }^{26}$ Considerando décimo, Corte Suprema, 2 de noviembre de 2000.
} 
Nos encontramos en los supuestos de hecho de uno de los ejemplos del artículo 2329 del Código Civil y así fue invocada la norma por el sentenciador de primera instancia. Sin embargo, la Corte Suprema alude a ella en términos generales sin mencionar los ejemplos del artículo y reitera que la responsabilidad de la demandada es por sus hechos propios al haber omitido sus deberes de vigilancia y seguridad. La Corte Suprema hace valer a la Ilustre Municipalidad de Puerto Montt la responsabilidad que conlleva la actividad que desempeña, en este caso, la atención de público en un consultorio de salud.

4. Contreras Cornejo, Irene Carolina con Ilustre Municipalidad de Concepción (2000): Corte Suprema, 28 de diciembre de 2000. Causa rol 4335-2000, No Legal Publishing 17821.

La Sra. Contreras demanda indemnización de perjuicios a la Ilustre Municipalidad de Concepción por la fractura de su tobillo derecho y otros daños ocasionados por el tropiezo de la actora con un hoyo sin señalizar en la esquina de calle Tucapel con O’Higgins en la comuna de Concepción. Funda su demanda en la falta de servicio de la municipalidad al incumplir un conjunto de normas que le imponen la obligación de comprobar que las veredas se presenten expeditas al tránsito de los peatones, manteniendo señales de advertencia para precaver a los usuarios de los peligros existentes en lugares públicos. La parte demandada rechaza completamente su responsabilidad: faltan los requisitos de culpa y de relación causal entre la acción y el daño. La responsabilidad por la mantención de las veredas y señalización corresponde a un tercero, el SERVIU, y la norma invocada por la demandante -artículo 174 inciso quinto de la Ley del Tránsito $^{27}$ - debe entenderse solo en el contexto de un accidente de tránsito que involucre vehículos motorizados.

Mantener una esquina con hoyos y sin resguardos es una cuestión que por su naturaleza es susceptible de atribuirse a culpa de la demandada, pues con mediana inteligencia puede concluirse que el lugar estaba en situación de provocar caídas de los peatones, lo que denota responsabilidad de la demandada. Es decir, se trata de un hecho de aquellos de los que ordinariamente provienen de negligencia. "Esto no significa otra cosa, entonces, que en el caso subjudice procede aplicar la presunción de culpabilidad que establece el artículo 2329 del Código Civil, desde que este precepto no solo cabe aplicarlo a los tres casos que enumera, pues estos están señalados solo a vía ejemplar y sin excluir otras situaciones" 28 .

Sin embargo, el tribunal sobreargumenta en un doble raciocinio que parece contradictorio. En efecto, el sentenciador invoca el artículo 174 señalado que establece que la municipalidad respectiva, o el fisco, en su caso, serán responsables civilmente de los daños que se causen con ocasión de un accidente que sea consecuencia del mal estado de las vías públicas o de su falta o inadecuada señalización. Por otra parte,

${ }^{27}$ Ley 18.290, publicada en el Diario Oficial el 7 de febrero de 1984.

28 Considerando décimo primero, Tribunal de Letras Concepción, 3 de septiembre de 1999, citando a Alessandri. 
considera que la culpa debe existir pero puede presumirse de conformidad a esta interpretación del artículo 2329. El problema es que al invocar al mismo tiempo la responsabilidad especial de la Ley del Tránsito y la civil, queda la duda si el argumento decisoria litis es el artículo 174 referido con un acento objetivo o bien el artículo 2329 en su interpretación de presunción de culpa.

La Corte de Apelaciones de Concepción confirmó la sentencia con fecha 6 de octubre de 2000, quedando ejecutoriado el fallo en la Corte Suprema el 28 de diciembre de 2000 al declarar desierto el recurso de casación en el fondo interpuesto por la demandada.

5. Werner Canales, Marta con Ilustre Municipalidad de Concepción (2001): Corte Suprema, 7 de mayo de 2001. Causa rol 1430-2000, No Legal Publishing 18590.

Con fecha 1 de mayo de 1993, la demandante cayó en un hoyo contiguo a un colector de aguas lluvias en la esquina de Avenida Irarrázabal con Palermo de la comuna de Concepción. En el lugar no había protección ni señalización que advirtiera el peligro que esto representaba para el tránsito peatonal, sufriendo la actora una fractura de tibia y peroné. Al igual que el caso comentado en el número anterior, la municipalidad se defendió negando su responsabilidad, pues no existe norma legal que disponga su obligación de mantener o señalizar las aceras o calles, labores que corresponden a la obligación de un tercero, el SERVIU.

Esta vez la Corte Suprema divide la argumentación de un modo más lógico. Fundamenta el fallo condenatorio en la responsabilidad establecida en el inciso final del artículo 174 de la Ley del Tránsito. Solo subsidiariamente hace mención al artículo 2329 del Código Civil, el que no fue objeto de impugnación por la vía de recurso de casación en el fondo, pese a sostener la interpretación de presunción de causalidad por hechos propios. El abogado redactor del fallo del máximo tribunal fue el profesor Barros quien, en su "Tratado de Responsabilidad Extracontractual" ya citado, sustenta y desarrolla la tesis de Alessandri. La sentencia considera que existe "una presunción de culpabilidad de la demandada por su hecho propio, según el artículo 2329 del Código Civil, que se infiere de la circunstancia de haber tenido la municipalidad la acera en estado de causar peligro a quienes transitaban en ella"29.

Como señala la Corte Suprema, el artículo 174 de la Ley del Tránsito se aplica indistintamente a vehículos y peatones. De acuerdo a lo establecido en los artículos 5 , 22 y 141 la Ley $N^{\circ} 18.695^{30}$ Orgánica Constitucional de Municipalidades, también invocada por la demandante, estos organismos sí tienen el deber de mantener los bienes nacionales de uso público -entre ellos, calles y aceras-, sin perjuicio de la responsabilidad de otras personas sobre instalaciones específicas. Ahora bien, dado que estas normas se considera les son aplicables a la demandada, se configura la responsabilidad estableci-

\footnotetext{
29 Considerando tercero, Corte Suprema, 2 de noviembre de 2000.

30 El D.F.L. No 1-19.704, fija el texto refundido, coordinado, sistematizado y actualizado de la Ley No 18.695 y publicado en el Diario Oficial el 3 de mayo de 2002.
} 
da en ellas "pues es caracteristico de este tipo de responsabilidad que baste que un accidente se haya producido a consecuencia de no haberse cumplido la función que la ley asigna a dicho órgano público para que la responsabilidad quede configurada"31.

Como se expresó para el caso anterior, no es necesario invocar el artículo 2329 del Código Civil si se estima que el caso se funda en normas específicas que establecen una responsabilidad objetiva. En efecto, en estos casos no se requiere aludir a presunción de culpa ningún tipo pues ella no es necesaria para configurar dicha responsabilidad.

6. Sergio Palma González con Municipalidad de Concepción (2002): Corte Suprema, 7 de mayo del 2002. Causa rol 1104-2002, No Legal Publishing 24432.

El Sr. Palma interpone demanda de indemnización de perjuicios en contra de la Ilustre Municipalidad de Concepción por las lesiones a su tendón de Aquiles y músculo gemelo. Las lesiones fueron causadas por su tropiezo con las baldosas sobresalientes de la vereda de la calle Barros Arana de dicha comuna, sin que el mal estado de la vía se encontrara advertido o señalizado. Funda su demanda, "en los daños que dice haber sufrido a consecuencia de la caída, debido a que no habia señalización del mal estado de la acera" 32 . La demandada solicitó el rechazo de la demanda argumentando que no se trata de una falta de servicio, dado que la construcción y la reparación de las aceras le corresponde al SERVIU. Señala que ha cumplido con la obligación exigida por el artículo 195 de la Ley No 18.290 y, además, sostiene que no hay ninguna relación de causalidad entre el supuesto incumplimiento de sus obligaciones y el daño cuya reparación se pretende.

Nuevamente la sentencia de segunda instancia argumenta con un doble raciocinio. Considera que ha quedado establecido el accidente y las lesiones sufridas por el actor. De acuerdo a la Ley 18.695 Orgánica Constitucional de Municipalidades, en su artículo 5 letra c) y otros artículos de la misma Ley ${ }^{33}$, se señalan como atribuciones esenciales que tienen los municipios para el cumplimiento de sus funciones "administrar los bienes municipales y nacionales de uso público existentes en la comuna, salvo que, en atención a su naturaleza o fines y de conformidad a la ley, la administración de estos últimos corresponda a otros órganos de la Administración del Estado"34. Así las cosas, corresponde la mantención de las aceras sub lite a la municipalidad demandada, sin que motivo alguno pueda justificar el incumplimiento de esta obligación. Con los antecedentes aclarados, concluye el sentenciador, la demandada se encuentra obligada a responder del daño producido al actor, porque se trata de un caso previsto en el artículo 174 de la Ley de Tránsito. "Se trata en este caso de la denominada responsabilidad objetiva, en que se prescinde del elemento culpabilidad, puesto que aqui basta que con una actividad o hecho se cause daño a la persona o a la propiedad de otro, para que nazca

\footnotetext{
31 Considerando quinto, Corte Suprema, 7 de mayo de 2001.

32 Considerando segundo, Tribunal de Letras de Concepción, 3 de abril de 2001.

33 Artículos $1^{\circ}, 3^{\circ}$ letra d), 40 letra f), 260 letra c), 63 letra f).

34 Considerando séptimo, Tribunal de Letras de Concepción, 3 de abril de 2001.
} 
el deber de responder de ép'35. Se acoge la tesis que el artículo 2329 del Código Civil configura una presunción de culpa y de relación causal entre la omisión negligente y el daño. A mayor abundamiento la sentencia cita a Alessandri: "Esto no significa otra cosa, entonces, que en caso sub judice procedería aplicar la presunción de culpabilidad que establece el artículo 2329 del Código Civil, desde que este precepto no solo cabe aplicarlo a los tres casos que enumera pues estos están señalados solo a vía ejemplar y sin excluir otras situaciones" 36 .

7. Gómez Parraguez, Jaime Eulogio con Sociedad Agrícola Cantalejos Limitada (2002): Corte Suprema, 7 de mayo de 2002. Causa rol 1187-2002, No Legal Publishing 24427.

Se trata de una demanda de indemnización de perjuicios presentada por el Sr. Gómez en representación de su hijo, con motivo del accidente laboral que sufrió el menor en las instalaciones de la demandada. El accidentado tiene 15 años de edad y fue contratado para las labores de operador de máquina calibradora de frutas en packing. Para poder supervigilar el funcionamiento de la máquina se le proporcionó un cajón al que debía subirse. Luego de 15 días de trabajo se quebró, por lo que el menor bajó bruscamente poniendo sus manos sobre la máquina, la que le cercenó todos los dedos de la mano derecha y el dedo pulgar de la mano izquierda, quedando con gravísima capacidad laboral de por vida.

La demandada solicita se rechace la demanda, señalando que los hechos fundantes no son efectivos. El menor habría sido contratado en calidad de "ayudante de operador de la máquina calibradora de frutas" y que, por ende, sus funciones eran otras. Lo que efectivamente habría ocurrido, es que el trabajador metió las manos en la máquina en movimiento, sin seguir el procedimiento regular que correspondía. En el caso que una fruta quedara atascada, se debía detener la máquina. Por ello la demandada alega que la única causal del accidente es la culpa del menor.

En primera instancia se desecha la demanda. Dado que no habría condena por delito o cuasidelito penal, no existiría responsabilidad extracontractual asociada ${ }^{37}$.

En sentencia de alzada la Corte de Apelaciones de Rancagua se pronuncia respecto del fondo del asunto. De acuerdo a la testimonial presentada en los autos y teniendo a la vista el expediente criminal No 10.734 del Segundo Juzgado de Letras de Santa Cruz, queda establecido "en forma inequivoca que la invalidez del menor Jaime Eulogio Gómez Parraguez, se produjo como consecuencia de un accidente del trabajo" y, en vista de ello, corresponde resolver al Tribunal "si dicho accidente se debió a culpa o negligencia por la que debe responder la demandada, o por el contrario, a imprudencia de

\footnotetext{
35 Considerando noveno, Tribunal de Letras de Concepción, 3 de abril de 2001.

36 Considerando décimo primero, Tribunal de Letras de Concepción, 3 de abril de 2001.

37 Expediente Criminal causa rol No 10.734 del Segundo Juzgado de Letras de Santa Cruz, "en el que la demandada no fue condenada por ningún delito o cuasidelito que permita hacer efectiva su responsabilidad extracontractual, sino que fue sobreseida de acuerdo al artículo $409 N^{\circ} 1$ del Código de Procedimiento Penal'. Considerandos décimo primero, décimo segundo y décimo tercero, Tribunal de Letras de Santa Cruz, 22 de agosto de 2001.
} 
la victima, o por último, a un hecho fortuito" 38 . De acuerdo a las pruebas presentadas en el proceso, en especial, Informe de Carabineros que da cuenta de las condiciones del lugar en el que se prestaban los servicios y a la inspección personal del tribunal realizada al packing del Fundo Santa Bernardita y, teniendo en cuenta lo dispuesto en el artículo 184 del Código del Trabajo, "cabe precisar que no existían a la época de los hechos, medidas de seguridad en el sitio de las faenas, y que la labor reseñada, de sumo peligrosa, no podía encargarse a un trabajador de escasa edad, como ocurrió en autos" 39. El sentenciador, citando Alessandri, explica que por los inconvenientes en materia de prueba que se fueron presentando en los accidentes sufridos por los trabajadores en actividades complejas y peligrosas "se fue adentrando en la jurisprudencia y la doctrina, el concepto de responsabilidad por el riesgo creado u objetiva" ${ }^{40}$. Así el legislador establece correctivos o presunciones de culpabilidad, como la consagrada en el artículo 2329 del Código Civil, aplicable en la especie. La Corte Suprema rechaza el recurso de casación en el fondo interpuesto por la demandada. Hace referencia a los hechos, la falta de diligencia en el actuar de la demandada, la no concurrencia de responsabilidad alguna de la víctima y lo resuelto por los sentenciadores del grado, sin hacer mención a la presunción del artículo 2329 del Código Civil. Concluye que la vulneración alegada del artículo 2329 y el artículo 2330 del Código Civil "solo podría tener lugar sobre la base de hechos diversos de aquellos fijados en la sentencia impugnada, únicos a los que debe sujetarse el Tribunal, que en la especie, procedió a acoger la indemnización de daño moral por haberse acreditado a través de los medios de prueba legales correspondientes la falta o diligencia del empleador en el cuidado de la vida y salud de sus trabajadores en el desempeño de sus labores" 41.

\section{Millapán Cocio, Juana Gualberta con Sociedad Austral de Electricidad S.A.} (2002): Corte Suprema, 14 de noviembre de 2002. Causa Rol 3436-2002, No Legal Publishing 26074.

Con fecha 26 de octubre de 1996 el contratista de la demandada ejecuta -a través de sus dependientes- las obras consistentes en el cambio del conductor de energía en el tendido eléctrico de Osorno a Puerto Octay. Antes del inicio de las obras, los supervisores de la demandada informaron al contratista que la corriente eléctrica se encontraba cortada, dando el pase para que se pudiera trabajar con seguridad. Sin perjuicio de lo anterior, al ejecutar los trabajos y cortar un cable central, los postes que lo sostenían cedieron en su base y la línea cortada se acercó a otra ajena a la demandada que sí estaba electrificada, lo que produjo un arco de corriente. A raíz de ello, falleció por electrocución el hijo de 21 años de la demandante, sobreviviendo el otro trabajador que estaba en servicio el que resultó solo con quemaduras.

${ }^{38}$ Considerando tercero, Corte de Apelaciones de Rancagua, 7 de marzo de 2002.

${ }^{39}$ Considerando sexto, Corte de Apelaciones de Rancagua, 7 de marzo de 2002.

${ }^{40}$ Considerando séptimo, Corte de Apelaciones de Rancagua, 7 de marzo de 2002.

${ }^{41}$ Considerando quinto, Corte Suprema, 7 de mayo de 2002. 
La Corte Suprema hace suyo el razonamiento del tribunal de primera instancia en el sentido que la demandada "no adoptó las medidas de seguridad necesarias para evitar el riesgo, en especial la normativa reglamentaria" ${ }^{\prime 2}$.

La demandada se defiende negando toda responsabilidad pues se trataría de la responsabilidad de un tercero (contratista). Además, existiría una exposición imprudente de la víctima al daño por cuanto no usó los medios ni la técnica adecuada para los trabajos en cuestión. Si así lo hubiese hecho no se habría producido el accidente, por lo que la demandada es ajena a la causa del accidente.

En una argumentación compartida por primera, segunda instancia y la Corte Suprema se establece que dado el giro de la demandada ella se encontraba obligada al cumplimiento de una normativa especial ${ }^{43}$, la que no se cumplió en el caso, pues la demandada no informó ni acordó con las empresas propietarias de las otras líneas eléctricas los trabajos a desarrollar tal como estaba obligada. La norma en cuestión establece que en el evento que una empresa eléctrica realice trabajos en instalaciones propias que puedan interferir en trabajos o instalaciones de otra empresa -si para cualquiera de ellas significa peligro para las instalaciones o personal, perturbaciones de servicios o daños de cualquier naturaleza- deben adoptarse de común acuerdo las medidas de seguridad adecuadas. En este caso la demandada no comunicó a la otra empresa los trabajos que pretendía hacer ${ }^{44}$.

La demandada es condenada por sus hechos propios; en este caso su propia omisión. En efecto, hizo menos de lo que le correspondía hacer como persona jurídica dedicada a una actividad regulada. El sentenciador estima que su omisión negligente -no reconocer la posibilidad del resultado dañoso- es la conducta sancionada en el artículo 2329 del Código Civil. La culpa infraccional o culpa contra la legalidad -no informar ni coordinar las medidas de seguridad con otras empresas involucradas- fue determinante para el resultado dañoso y por ello base del resultado judicial en su contra.

La empresa que desarrolla una actividad regulada no se desliga de los daños que acarree el incumplimiento de la normativa legal o reglamentaria a la que está obligada por el hecho de haber tercerizado los servicios. No se trata, por tanto, de la responsabilidad por el hecho de un tercero sino por hechos propios. La norma fuente de responsabilidad es el artículo 2329 del Código Civil y no el artículo 2320, que establece la responsabilidad por los dependientes.

9. Concha Villagrán, Ramón Jesús y otros con Palma Barra, Francisco y otros, Corte de Apelaciones de Concepción, 6 de octubre de 2008. Causa rol 2228-2004, No Legal Publishing $40412^{45}$.

\footnotetext{
42 Considerando tercero, Corte Suprema, 14 de noviembre de 2002.

43 Reglamento de instalaciones eléctricas de corrientes fuertes, Norma Técnica N.S.E.G. 5 E n71.

${ }^{44} \mathrm{La}$ demandada alega que esta norma no es absoluta sino que debe interpretarse en el contexto, por cuanto no era necesaria esa comunicación si se habían tomado otras medidas como la contratación de personal competente, equipo adecuado, desenergización de las instalaciones propias, conexión a tierra, etc. 45 Con fecha 4 de marzo de 2009 se produjo el desistimiento de los recursos de casación interpuestos.
} 
En la mañana del 20 de marzo de 2003 el Sr. Palma, conduciendo un camión cargado, atropella a un joven de 17 años con la parte posterior derecha del vehículo, en el acceso a las obras de ampliación de un establecimiento educacional.

Las obras consistentes en la ampliación del Liceo Politécnico A 46, Rosaura Santana Ríos, fueron encargadas por la Ilustre Municipalidad de Lota a Ingetal Ingeniería y Construcción S.A.

El acceso a las obras, desde un pasaje de ripio -vía pública-, era angosto (2,9 metros), en pendiente de bajada y con diversas complejidades físicas dado que los vehículos debían virar inmediatamente de ingresado al recinto pues existía un barranco en la línea recta.

El conductor fue condenado por su manejo imprudente, dado que como el mismo reconoció vio antes de ingresar a las obras a un grupo de jóvenes, quienes quedaron al costado derecho del camión. Debido a la pendiente del acceso, el conductor al ingresar solo visualiza con el espejo retrovisor derecho el cielo y no el pasaje. Sin embargo, el chofer no se detuvo pese a haber perdido la retrovisualización del grupo. La Corte respectiva, estima le es aplicable el artículo 114 de la Ley del Tránsito, que establece a los conductores la obligación de mantenerse atento a las condiciones del tránsito del momento y, en especial, el artículo $172 \mathrm{~N}^{\circ} 2$ que presume la responsabilidad del chofer en los accidentes del tránsito por no estar atento a dichas condiciones.

Por su parte, a la municipalidad y a la contratista, les hace aplicable el artículo 2329 del Código Civil. Citando a Barros estima que dicha norma contiene "una presunción legal de responsabilidad por el hecho propio, aplicable al caso en que el daño proviene de una actividad caracterizada por una especial peligrosidad, cuya ejecución requiere de medidas de extremo resguardo por quienes tienen el control de los hechos" 46 .

Para la Ilma. Corte de Concepción las actividades encargadas por la municipalidad y ejecutadas por la contratista les obligaban a comportarse de manera de no causar daño. Se les exige haber examinado las condiciones del terreno para que, pese a las dificultades, pudieren ingresar los camiones cargados de un modo seguro durante las maniobras de acceso. En este mismo sentido, se considera que ellas debieron haber previsto la contratación de personal que orientara al conductor en la entrada a las obras omisión, que dada las circunstancias, se estima negligente. Además, se le da valor de plena prueba a la declaración pública emanada de dos profesores, que representaron una advertencia previa y clara de los peligros de la ejecución de las obras por ser un sector de circulación de estudiantes y público en general.

"Asi las cosas, habiéndose debido el atropello y fallecimiento de Fabián Concha Navarro, precisamente, al ingreso de un camión con carga, en esas peligrosas circunstancias, que se encontraban bajo el control y dominio de la I. Municipalidad de Lota y de Ingetal Ingeniería y Construcción S.A., que no se adoptaron las exigibles medidas de seguridad, sus respectivas responsabilidades reparatorias, por sus hechos propios, deben ser legalmente presumidas, al tenor de lo dispuesto en el inciso primero del artículo 2329 del Código Civil; las deman-

${ }^{46}$ Considerando vigésimo quinto, Corte de Apelaciones de Concepción, 6 de octubre de 2008. 
dadas no han producido en la causa pruebas plenas que permitan desvirtuar la presunción legal de responsabilidad" 47 . Ambas demandadas -así como el conductor- deben responder solidariamente de los daños causados por sus respectivas conductas omisivas negligentes de conformidad al artículo 2317 del Código Civil.

Por su parte, la empresa dueña del camión Áridos y Transportes La Cabaña Limitada responde también solidariamente de los daños causados pero por la aplicación de lo dispuesto en el artículo 174 de la Ley del Tránsito.

\section{Lira Montes, Jorge Luis y otros con Shell Chile Sociedad Anónima Comercial e} Industrial (2008): Corte Suprema, 29 de enero de 2008. Causa rol 4318-2006, No Legal Publishing 38357.

El contrato de transporte entre el contratista -transportista- y la demandada establecía que el tiempo de conducción de cada chofer no debía exceder el máximo legal, ajustándose así a las medidas preventivas del reglamento aplicable. Sin embargo, el chofer condujo catorce horas antes del accidente de tránsito que le costó la vida a un menor y dejó con serias lesiones al resto. El informe S.I.A.T., acompañado al expediente criminal en contra del conductor, concluye que el accidente se debió a que este guiaba el camión en condiciones físicas deficientes (somnolencia), lo que lo llevó a quedarse dormido por breves instantes cruzando el eje de la calzada y chocando de frente al otro automóvil.

La sentencia considera coherente el traslado de la carga probatoria a la demandada pues es ella quien debe acreditar el cumplimiento de obligaciones reglamentarias a las que estaba sujeta. Cambia la regla general, pues no es la víctima la que debe probar la culpa sino la demandada su inocencia. En una actividad regulada, quien ejerce la actividad (demandada) debe acreditar que cumplió la normativa reglamentaria a la que estaba sujeta. No existe para la demandada, entonces, un perjuicio en el modo de apreciar el onus probandi siendo por ello improcedente el recurso de casación a este respecto.

En los hechos, pese a que la demandada externalizó los servicios de transporte de combustible, se reservó contractualmente el derecho de inspección del vehículo de transporte, fiscalización del cumplimiento de las normas de seguridad aplicables y el control directo sobre los conductores, dando cumplimiento formal a las normas del Decreto Supremo No 90 de 1996 del Ministerio de Economía ${ }^{48}$. De conformidad al fallo, el cumplimiento efectivo de la normativa aplicable que regula el transporte y distribución del combustible debe ser acreditado por la demandada.

La sentencia superior pese a corregir argumentativamente la sentencia apelada en aspectos como responsabilidad de los dependientes y responsabilidad objetiva, confirma la interpretación del artículo 2329 del Código Civil en el sentido que esta norma establece ciertas presunciones de responsabilidad que invierten el peso de la prueba si el daño deriva de haberse infringido el deber de adoptar las medidas de vigilancia tendientes a prevenir el daño.

\footnotetext{
${ }^{47}$ Considerando vigésimo quinto, Corte de Apelaciones de Concepción, 6 de octubre de 2008.

48 El D.S. 90 del Ministerio de Economía, Fomento y Reconstrucción publicado en el Diario Oficial el 5 de agosto de 1996 y aprueba el Reglamento de seguridad para el almacenamiento, refinación, transporte y expendio al público de combustibles líquidos derivados del petróleo.
} 
En definitiva, la Corte Suprema estimó que la prueba rendida por la demandada estaba dentro del ámbito de su carga probatoria y fue calificada como insuficiente como defensa por lo que debía asumir su responsabilidad en los hechos.

El no cumplimiento de las exigencias legales o reglamentarias nos posicionan frente a la llamada culpa contra la legalidad o culpa infraccional. En el evento de incumplimiento es la empresa regulada la que debe probar una defensa liberatoria. Si la infracción es indubitada y median daños no es de extrañar que se recurra a la interpretación que Alessandri dio al artículo 2329 del Código Civil. La responsabilidad civil fundada en la culpa legal o infraccional se aplica directamente al sujeto regulado, aun cuando medie la externalización de los servicios.

11. Inversiones Rochet Hermanos Ltda y otra con Refinería de Petróleo de Concón S.A. (2009): Corte Suprema, 5 de enero de 2009. Causa rol 2380-2008, No Legal Publishing 41523.

El caso trata de una demanda de indemnización de perjuicios entablada por dos sociedades dueñas de los terrenos por donde pasa una cañería del oleoducto de propiedad de la demandada. Entre las sociedades demandantes y la demandada existían sendas escrituras públicas que regulaban el otorgamiento de una servidumbre de paso. La cañería se rompió y se produjo un derrame de petróleo crudo con la consecuente contaminación del suelo, vegetación, aguas superficiales y subterráneas existentes en los predios afectados. Fundan su pretensión en que la demandada habría vulnerado diversas disposiciones del Decreto Supremo No 90, de 1996, del Ministerio de Economía y el artículo 2314 del Código Civil, ya que "no adoptó todas las medidas de seguridad y de prevención que le son exigidas a la misma para el transporte de combustible líquido a través de oleoductos” ${ }^{49}$. Por su parte, Refinería de Petróleo de Concón S.A. solicita se rechace la demanda. Expone que se trata en la especie de una responsabilidad contractual y no aquiliana "como erróneamente la califican los demandantes" 50 . Por lo anterior, la ley del contrato prima sobre las disposiciones del Decreto Supremo No 90, que por lo demás "rigen las relaciones entre la autoridad, Superintendencia de electricidad y combustible y los particulares dueños o administradores del oleoducto, regulando la responsabilidad administrativa correspondiente" 51 . El tribunal de primera instancia niega lugar a la demanda de indemnización de perjuicios por considerar que hay "una errónea elección por parte de la actora, del estatuto de responsabilidad que debió ser aplicado, y no obstante la acreditación de los perjuicios provocados, a esta magistrado le resulta vedado acoger la acción promovida, toda vez que incurriría sin lugar a dudas en el vicio de ultra petita" 52 .

La Corte de Apelaciones de Valparaíso estableció que pese a existir contratos por escritura pública que daban fe de una servidumbre de paso, los daños reclamados por los demandantes no son consecuencia directa de esa vinculación " $y$ se han producido por

\footnotetext{
${ }^{49}$ Considerando primero, Tribunal de Letras de Viña del Mar, 27 de octubre de 2006.

${ }^{50}$ Considerando segundo, Tribunal de Letras de Viña del Mar, 27 de octubre de 2006.

51 Considerando segundo, Tribunal de Letras de Viña del Mar, 27 de octubre de 2006.

52 Considerando trigésimo cuarto, Tribunal de Letras de Viña del Mar, 27 de octubre de 2006.
} 
eventos que superan la situación contractual de las partes" $" 53$. En efecto, el tribunal considera que no existen en los contratos de servidumbres pactados obligaciones contractuales que digan relación con los daños que en definitiva se produjeron, y que son objeto de la demanda, por lo que debe aplicarse la normativa reglamentaria existente y las disposiciones atinentes del Código Civil. La norma civil que la Corte estima aplicable es justamente el artículo 2329 del Código Civil que establece "una suerte de presunción de responsabilidad, el que en general reconoce dos grupos de casos: las actividades particularmente peligrosas y los casos en el que daño prima facie ha sido causado por negligencia" 54 .

A esta Ilustrísima Corte le resulta evidente que es la demandada la responsable de la seguridad, tanto de la puesta en marcha como de la continuidad de la operación de la empresa, "debiendo controlar al máximo, como una obligación ineludible, los riesgos derivados de posibles derrames" 55 .

Sin perjuicio que exista una vinculación contractual entre las partes, si los daños no son consecuencia directa de esta relación se tratan como extracontractuales para los efectos de la responsabilidad civil que engendran. Ahora bien, dentro del estatuto de responsabilidad extracontractual decidido aplicar, el artículo 2329 del Código Civil constituye en sí mismo una fuente primaria de responsabilidad, sin necesidad del invocar el artículo 2314 del mismo Código. Acoge la Corte de Apelaciones de Valparaíso la posición de Barros, en el sentido que se puede presumir responsabilidad en ciertos casos de actividades peligrosas o en aquellos en que el daño prima facie ha sido causado por culpa ${ }^{56}$.

Se adhiere a la tesis que el artículo 2329 del citado cuerpo legal establece una fuente de responsabilidad por un hecho propio (u omisión), a través de la configuración de una presunción de culpa y de la relación causal entre la omisión negligente y el daño, sin que la demandada haya probado una causal de irresponsabilidad.

\section{CONCLUSIONES}

1. La presunción de culpabilidad que reconoce Alessandri ha sido recogida por parte de nuestra jurisprudencia, tanto por los tribunales de primera instancia, Cortes de Apelaciones e incluso Corte Suprema, los que desarrollan dicho fundamento en sus sentencias.

2. Es necesario distinguir presupuestos de responsabilidad objetiva, los que deben estar expresamente establecidos en leyes especiales, de la presunción de culpabilidad del

\footnotetext{
53 En efecto, la demandada alega un hecho fortuito (en un ámbito de responsabilidad contractual) mientras las demandantes acusan negligencia extracontractual de la Refinería de Petróleo de Concón al incumplir el deber de mantener las instalaciones - corroídas por el paso del tiempo- de forma de impedir o reducir filtraciones que pudieran causar daño, de conformidad al artículo 1 del D.S. No 90 del Ministerio de Economía, de 5 de agosto de 1996.

54 Considerando décimo, Corte de Apelaciones de Valparaíso, 29 de enero de 2008. Este considerando continúa su redacción citando a Enrique Barros, quien como vimos, estima que el artículo 2329 del Código Civil establece una presunción de culpabilidad y causalidad continuando la misma línea de pensamiento de Alessandri.

55 Considerando noveno, Corte de Apelaciones de Valparaíso, 29 de enero de 2008.

56 BARROS (2007) p. 151
} 
artículo 2329 del Código Civil. La innecesaria argumentación en doble línea de las sentencias confunde los conceptos. El hecho que haya existido culpa es irrelevante jurídicamente si el supuesto normativo que se considera aplicable es de responsabilidad objetiva.

3. La responsabilidad por la supervisión, fiscalización o control de ciertas actividades no son delegables en terceros, aunque si lo sean los servicios. En efecto, producido un daño, si se han infringido normas de seguridad aplicables a la actividad que desempeñan deberán responder a las víctimas por sus hechos propios. Otro juicio será el de la empresa regulada - por responsabilidad contractual o extracontractual- contra los que directamente ejecutaron los hechos dañosos.

4. El artículo 2329 del Código Civil puede ser de gran utilidad en materia de responsabilidad civil. Las personas naturales o jurídicas que realizan una actividad regulada deben cumplir la normativa que les es aplicable. De lo contrario, los criterios jurídicos como prima facie, res ipsa loquitur, culpa infraccional, culpa contra la legalidad y culpa anónima o virtual pueden ser usados para interpretar el artículo señalado como una presunción de responsabilidad en su contra, en la medida que concurran los demás requisitos legales.

5. Sin perjuicio de lo señalado, a nuestro juicio esta presunción debe operar solo en algunos supuestos, que no quedan reducidos a los ejemplos establecidos en el mismo artículo por el legislador, ya que no es taxativo, pero que se constriñen principalmente a actividades en donde al agente causante del daño le es exigible una diligencia especial por la naturaleza de la actividad que desempeña.

\section{BIBLIOGRAFÍA CITADA}

ALESSANDRI, Arturo (1943): De la responsabilidad extracontractual en el derecho civil chileno (Santiago, Imprenta Universitaria) 716 pp.

BARROS, Enrique (2007): Tratado de responsabilidad extracontractual (Santiago, Editorial Jurídica de Chile) 1230 pp.

Claro, Luis (1937): Explicaciones de derecho civil chileno y comparado, edición 1977, volumen XI (Santiago, Imprenta Nascimento) $812 \mathrm{pp.}$

CORRAL, Hernán (2003): Lecciones de responsabilidad civil extracontractual (Santiago, Editorial Jurídica de Chile) 423 pp.

DuCCI, Carlos (1936): Responsabilidad civil (Ex-contractual), Memoria de prueba de la Universidad de Chile (Santiago, Empresa Periodística El Imparcial) 228 pp.

MEZA, Ramón (2006): Manual de derecho Civil. Fuentes de las obligaciones (Santiago, Editorial Jurídica de Chile) 372 pp.

RAMOS, René (2006): De la responsabilidad extracontractual (Santiago LexisNexis) 151 pp.

RODRÍGUEZ, Pablo (2002): Responsabilidad extracontractual (Santiago, Editorial Jurídica de Chile) 505 pp.

TAPIA, Orlando (1941): De la responsabilidad civil en general y de la responsabilidad delictual entre los contratantes, edición 2006 (Santiago, LexisNexis) 654 pp. 
